\title{
EDITORIAL
}

\section{AS MUDANÇAS E A IMPORTÂNCIA DA LUTA}

O primeiro número da Comunicações em 2019 chega em um momento em que passamos por muitas mudanças no cenário político e educacional. Essas mudanças provocam sensações de instabilidade e insegurança constantes, pois já não sabemos mais qual a próxima conquista a ser perdida. Ora, se as sucessivas investidas contra as conquistas sociais tendem a causar desânimo, elas também podem servir para nos lembrar da importância de não abandonar a luta. No campo da educação, uma forma importante de enfrentar os desafios que surgem passa por aprofundar o debate teórico a respeito da educação que queremos. Nesse sentido, mais uma vez, a Comunicações busca contribuir com esse debate

Nesse número apresentamos 11 artigos submetidos em fluxo contínuo, um ensaio, duas resenhas e quatro artigos que compõem o dossiê "Lazer, Educação e Tecnologia". Os autores desses textos provêm de 8 estados do Brasil, sendo: São Paulo, Minas Gerais, Paraná, Santa Catarina, Mato Grosso, Mato Grosso do Sul, Pernambuco e Amazonas.

Em "Concepções de qualidade nos documentos oficiais sobre a Educação Superior", José Carlos Rothen, Regilson Maciel Borges, Andreliza Cristina de Souza, Joelma dos Santos Bernardes e Pamela Cristina Botiglieri discutem os resultados de uma pesquisa que teve como objetivo identificar o conceito de qualidade da Educação Superior presente nos documentos oficiais e dispositivos legais brasileiros. Os autores não identificaram uma definição única do que seria qualidade, mas observaram que o termo varia entre uma visão formativa-educativa e uma visão gerencialista.

Jaqueline Cristina da Silva e Géssica Priscila Ramos, no artigo intitulado "Indicações oficiais e resultados iniciais da política de ampliação do Ensino Fundamental", buscam relacionar os resultados das pesquisas sobre o ensino fundamental de nove anos com o amparo oficial referente ao Programa Ampliação do Ensino Fundamental para Nove Anos no Brasil. A partir das discussões, concluem que a ampliação desse nível de ensino foi realizada sem a preparação de professores e gestores.

Por sua vez, Antonio Serafim Pereira, em "Reforma e inovação educativas: o cotidiano como perspectiva de análise", apresenta a temática da inovação educativa a partir do cotidiano escolar, evidenciando uma perspectiva de análise que parece abarcar a complexidade dessa temática.

O texto "Narrativas de professores sobre seu percurso na licenciatura: contribuições para os formadores", de autoria de Renata Cristina Oliveira Barrichelo Cunha, Cláudia Be-

Comunicações $\mid$ Piracicaba $\mid$ v. $26 \mid$ n. $1 \mid$ p. 1-3| jan.-abr. 2019 
atriz de Castro Nascimento Ometto e Guilherme do Val Toledo Prado, discute as narrativas autobiográficas de professores como materiais de investigação e experiências de formação. Após as análises, os autores destacam a centralidade do conhecimento nos processos de formação; os modos de mediação do conhecimento pelo professor formador; a relação entre teoria e prática com enfoque para as práticas de estágio e de pesquisa.

Bruna Mendes Muniz e Klinger Ciríaco apresentam os resultados de uma pesquisa sobre o trabalho pedagógico com conteúdos matemáticos em uma classe multisseriada. Assim, em "Descobrindo o início da docência em Matemática na classe multisseriada" os autores apresentam caminhos para a aprendizagem matemática dos alunos de classes multisseriadas.

Em "Prática docente em foco: um estudo sobre integração dos saberes na educação do campo", Maria Joselma do Nascimento Franco e Maria Madalena da Silva apresentam resultados de pesquisa que buscou compreender como a integração dos saberes é tratada nas práticas dos docentes atuantes em escolas do campo. Essas autoras concluem que a compreensão que as docentes têm sobre integração de saberes se distancia da concepção que a norteia na Educação do Campo.

Ivone Rodrigues dos Santos e Régis Henrique dos Reis Silva, em artigo intitulado "Bases teórico-pedagógicas do atendimento educacional especializado em duas redes municipais de ensino no Brasil", discutem as bases teórico-pedagógicas que subsidiam as orientações para a organização do Atendimento Educacional Especializado (AEE) em duas redes públicas municipais de ensino.

$\mathrm{O}$ artigo "O espetáculo de si: uma proposição sobre a atualidade da sociedade do espetáculo", de autoria de Marsiel Pacífico e Luiz Roberto Gomes, aborda o cenário atual, no qual a imagetização da vida ganha centralidade, e sustenta que podemos estar vivendo um terceiro momento do capital, ao qual os autores se referem como "o espetáculo de si".

Helga Caroline Peres e Luiz Roberto Gomes, autores do artigo "Do sentido formativo ao enigma da frieza: uma análise do filme 'A fita branca', de Michael Haneke", referenciados na Teoria Crítica, discutem os conceitos de formação e de frieza burguesa ao analisar o filme referenciado no título.

"O Recado do Morro: a estória da experiência formativa de Pedro Orósio", de autoria de Bruno Pucci, Gloria Bonilha Cavaggioni e Luis Fernando Altenfelder de Arruda Campos" apresenta uma interpretação do conto "Recado do Morro", de Guimarães Rosa, em diálogo com as reflexões estético-filosóficas de Theodor Adorno.

Mirian de Medeiros, em "A pobreza na Congregação das Irmãs Escolares de Nossa Senhora à luz de Enrique Dussel e Paulo Freire" aborda a questão da pobreza em uma congregação religiosa, discutindo os sentidos que ela assume em uma perspectiva crítica de análise.

Na seção "Ensaios", temos "O documentário de divulgação científica: tipos e potencialidades de uso no ensino de Ciências", de Aldo Aoyagui Gomes Pereira, Silmara Rodrigues Domingues e Aline Rodrigues de Carvalho, que aborda o trabalho com documentários em uma disciplina de Prática de Ensino de Física, evidenciando o potencial destes recursos para a discussão de questões envolvendo a natureza da ciência e debates sociocientíficos. 
Na seção "Resenhas", Eliane Santana Dias Debus, apresenta a obra "O Gil e a Bola Gira e Outros Poemas para Brincar: um convite à brincadeira", do autor moçambicano Celso Celestino Cossa, publicado em 2016 pela chancela da Escola Portuguesa de Moçambique.

Ainda na seção "Resenhas", o livro "Mudança estrutural da esfera pública", de Jürgen Habermas, é apresentado por Felipe Mattei Martins e Artur José Renda Vitorino.

Por fim, temos ainda quatro artigos que compõem o "Dossiê Lazer, Educação e Tecnologia" cuja apresentação é feita oportunamente pela professora Cinthia Lopes da Silva.

Que a leitura seja proveitosa e que sirva para que possamos aprofundar nossa compreensão a respeito da educação.

Andreza Barbosa

Editora 